\title{
RESEARCH
}

Open Access

\section{Fragmented QRS complex frequency and location as predictor of cardiogenic shock and mortality following acute coronary syndrome}

Ahmad Salah Younis, Moataz Ibrahim El-Halag, Mahmoud Ali ElBadry and Nora Ismail Mohamed Abbas* (D)

\begin{abstract}
Background: Worldwide, coronary heart disease (CHD) is topping the foremost important chief causes of mortality. Fragmented QRS (f-QRS) is a pattern of QRS complex in 12 leads surface ECG which showed a promising value in predicting the outcome in cardiac diseases including ischemic heart disease.

We aimed to research the importance of using $\mathrm{f}$-QRS as a non-invasive and cheap tool for the prediction of cardiogenic shock and mortality in acute coronary syndrome (ACS).

Methods: A retrospective study includes eighty four critically ill ACS patients. Patients were classified consistent with the presence or absence of fragmented QRS into two groups (46 and 38 patients respectively). Exclusion criteria include past history of important ischemic events ( $\mathrm{Ml}, \mathrm{PCl}$, and $\mathrm{CABG}$ ), permanent $\mathrm{AF}$, and/or cardiomyopathy.

No statistical significant differences were detected between the 2 groups as regards the age, gender, major risk factors of ischemic heart condition, cardiac bio-markers, Killip class, LVEF, updated GRACE risk score of ACS, and inhospital mortality.

Results: A number value of f-QRS leads $>3$ yields sensitivity and specificity ( $83.3 \%$ and $72.5 \%$ respectively) for predicting hospital mortality. The f-QRS group was further split-up according to the numbers of f-QRS leads into 2 subgroups; subgroup (A1) including patients with $>3 \mathrm{f}$-QRS leads and subgroup (A2) including patients $\leq 3 \mathrm{f}-\mathrm{QRS}$ leads. Subgroup (A2) showed considerable difference as regards some important variables including a higher SBP ( $P$ $=0.016)$, a slower HR $(P=0.014)$, a lower up-dated GRACE risk score (3.22 \pm 6.95 vs $6.81 \pm 12, P$ value 0.048$)$, and a lower rate of hospital death (1/30 vs. 5/16, $P=0.015)$. Anterior f-QRS showed statistically significant higher HR, lower SBP, a higher frequency of shock, a higher updated GRACE risk score, and a higher chance of in-hospital mortality $(P=0.004)$ compared to non-anterior f-QRS.
\end{abstract}

Conclusion: The position and number of $\mathrm{f}$-QRS leads provide a non-invasive and a readily accessible tool to predict the prognosis, occurrence of cardiogenic shock, and in-hospital mortality.

\footnotetext{
* Correspondence: Narnar_77@yahoo.com; narnaris@kasralainy.edu.eg

Department of Critical Care Medicine, Faculty of Medicine, Cairo University, Kasr alAiny Street, Cairo 11562, Egypt
}

\section{SpringerOpen}

(c) The Author(s). 2020 Open Access This article is licensed under a Creative Commons Attribution 4.0 International License, which permits use, sharing, adaptation, distribution and reproduction in any medium or format, as long as you give appropriate credit to the original author(s) and the source, provide a link to the Creative Commons licence, and indicate if changes were made. The images or other third party material in this article are included in the article's Creative Commons licence, unless indicated otherwise in a credit line to the material. If material is not included in the article's Creative Commons licence and your intended use is not permitted by statutory regulation or exceeds the permitted use, you will need to obtain permission directly from the copyright holder. To view a copy of this licence, visit http://creativecommons.org/licenses/by/4.0/. 


\section{Background}

Consistent with [16], ischemic heart diseases (IHD) is a major explanation of death and disability in developed countries. It is accountable for about one-third or more of all mortality in individuals over age 35.

Flowers and associates since 1960s [9] were the primary researcher to examine the slurring and morphological changes in QRS complex and documenting the presence of $f-Q R S$ complexes fragmented QRS (f-QRS) as defined by [5], is that the occurrence of an additional (extra) $\mathrm{R}$ wave $\left(\mathrm{R}^{\prime}\right)$ or notching within the nadir of the $\mathrm{S}$ wave, or the existence of $>1 R^{\prime}$ (fragmentation) in 2 contiguous ECG leads, regarding a significant coronary artery territory. Moreover, fragmentation in wide complex QRS, i.e., $\geq 120 \mathrm{~ms}$ (BBB and paced rhythms) was defined in [6] by Das and associates as various RSR' patterns with or without a $\mathrm{Q}$ wave, with $>2 \mathrm{R}$ waves $\left(\mathrm{R}^{\prime}\right)$ or $>2$ notches within the $R$ wave, or $>2$ notches within the down-stroke or upstroke of the $\mathrm{S}$ wave, in 2 contiguous leads regarding a significant coronary artery territory in fragmented $\mathrm{BBB}$ and also the presence of $>2 \mathrm{R}^{\prime}$ or $>$ 2 notches within the $\mathrm{S}$ waves in 2 contiguous leads in fragmented paced QRS. Torigoe and colleagues concluded that the quantity of leads with $\mathrm{f}-\mathrm{QRS}$, especially the presence of $\geq 3$ leads with $f$-QRS, is an independent predictor of cardiac death or hospitalization for heart failure in 170 patients with prior MI.

[7] studied the usefulness of fragmented QRS on a 12lead electrocardiogram. Serial electrocardiograms from 896 patients with ACS (104 with STEMI, 337 with NSTEMI, and 455 with UA) were obtained every 6 to 8 $\mathrm{h}$ during the initial $24 \mathrm{~h}$ after the diagnosis of MI and also the following day $(<48 \mathrm{~h})$. Fragmented QRS developed in 224 patients (51\%) in the MI group and only 17 (3.7\%) in the UA group. Kaplan-Meier survival analysis revealed that patients with $\mathrm{f}-\mathrm{QRS}$ had significantly decreased time to death compared to those without $f-Q R S$. Additionally, the presence of $\mathrm{f}-\mathrm{QRS}$ at the 48th hour could be a significant predictor of major adverse cardiac events (MACE) in STEMI patients who have undergone primary PCI consistent with [2].

Our aim was to research the worth of using $f-Q R S$ as a non-invasive and cheap tool for the prediction of cardiogenic shock, prognosis, and mortality in acute coronary syndrome (ACS).

\section{Methods}

From our medical records of patients admitted between November 2013 and April 2015, this retrospective study was conducted on 84 patients (67 males and 17 females) aging between 29 and 80 years admitted to the Critical Care Department with acute coronary syndrome (ACS). They were divided by 12 leads surface ECG within 2 days of admission into two groups; group A that features 46 patients with f-QRS and group $\mathrm{B}$ that has 38 patients without f-QRS. Patients with major ischemic events (prior myocardial infarction, PCI, CABG), permanent $\mathrm{AF}$, and/or myocardial diseases were excluded.

The available medical records of the patients were reviewed for routine medical history, clinical examination including SBP and HR on admission, the risk factors of $\mathrm{CHD}$, routine laboratory measurements including cardiac bio-markers and echocardiography.

ECGs were analyzed for (1) detection of fragmented QRS (f-QRS) within the initial 2 days using diagnostic criteria defined by $[5,6]$. (2) Localization of f-QRS: Anterior $\mathrm{f}$-QRS was defined by the presence of $\mathrm{f}-\mathrm{QRS}$ in 2 contiguous anterior leads (V1 to V5), lateral f-QRS was defined by the presence of $\mathrm{f}-\mathrm{QRS}$ in 2 contiguous lateral leads (I, aVL, and V6), and inferior $\mathrm{f}-\mathrm{QRS}$ was defined by the presence of $f-Q R S$ in 2 contiguous inferior leads (II, III, and aVF) consistent with [10]. (3) Count the amount of leads with fragmented QRS (at least 2 contiguous leads reminiscent of a significant coronary artery territory) (Fig. 1).

Our outcomes were Killip class, LVEF, calculated updated GRACE risk score, and in-hospital death as a short-term MACE.

Statistical data were described in terms of mean \pm standard deviation ( \pm SD), median and range, or frequencies (number of cases) and percentages when appropriate. Comparison of numerical variables between the study groups was done using Student $t$ test for independent samples in comparing 2 groups of normally distributed data and/or large groups and Mann Whitney $U$ test for independent samples for comparing not-normal data and whenever appropriate. When comparing categorical data, chi-square $\left(\chi^{2}\right)$ test was applied. Exact test was performed instead when the expected frequency is fewer than 5. Correlation between different variables was done using Spearman rank correlation equation. Accuracy was represented by means of the terms sensitivity and specificity. Receiver operator characteristic (ROC) analysis was used to determine the optimum cutoff value for number of leads with $\mathrm{f}-\mathrm{QRS}$ in diagnosing important outcomes. $P$ values $<0.05$ was considered of statistical significance.

\section{Results}

- Of the 84 patients data analyzed, 46 patients had fQRS (group A) while 38 patients did not have (group B). The study showed no significant differences between both groups as regards general demographic characteristics, the major risk factors of CHD including HTN, DM, dyslipidemia, and smoking or SBP and HR on admission. Also, in terms of abnormal cardiac bio-markers, Killip class, updated 


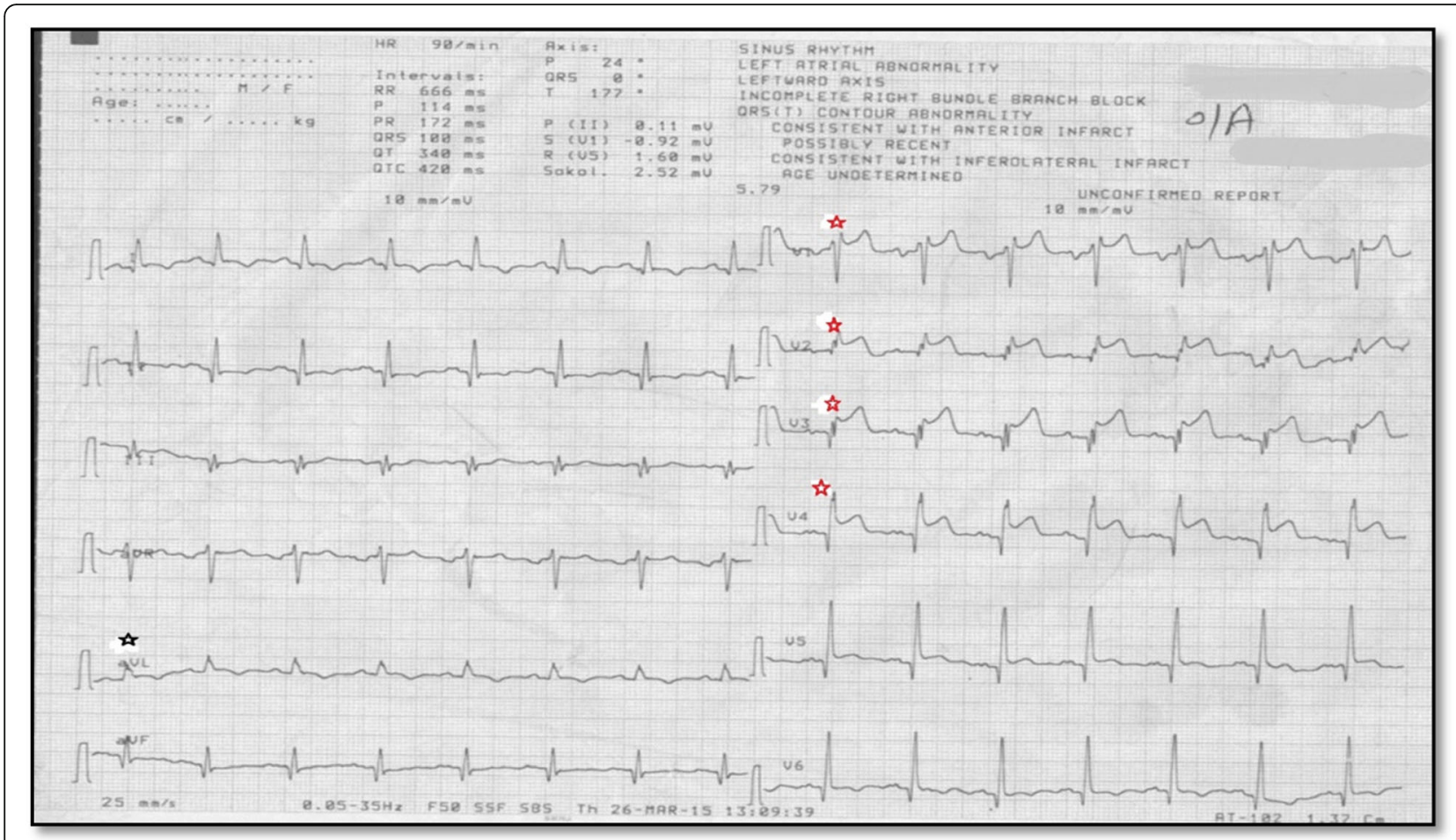

Fig. $1 \mathrm{f}-\mathrm{QRS}$ in $\mathrm{V} 1-\mathrm{V} 4$ (anterior $\mathrm{f}-\mathrm{QRS}$ ). Note that isolated $\mathrm{f}-\mathrm{QRS}$ in aVL does not count as lateral $\mathrm{f}-\mathrm{QRS}$

GRACE risk score, and in-hospital death, we could not find any significant difference between the cases and controls group (Table 1).

- Eighteen patients (39\% of group A) had f-QRS in 2 leads, 12 patients (26\% of group A) had f-QRS in 3 leads while the rest of patients in this group had $\mathrm{f}$ QRS in 4 to 8 leads.

The ROC curve showed that the optimal cutoff value of f-QRS leads is > $3 \mathrm{f}$-QRS leads for predicting hospital mortality with $83.3 \%$ sensitivity and $72.5 \%$ specificity. Area under the curve AUC $=0.796 ; 95 \% \mathrm{CI}=0.651$ to $0.900(P=0.015)$ (Fig. 2).

- Impact of number and location of $f$-QRS. The fragmented QRS cases group was further subdivided into 2 subgroups according to the numbers of $\mathrm{f}-\mathrm{QRS}$ leads. Subgroup (A1) included patients with four fQRS leads or more and subgroup (A2) included patients with 3 or fewer f-QRS leads. Subgroup (A1) showed statistically significant difference lower SBP $(111.33 \pm 25.03 \mathrm{mmHg}$ vs. $139 \pm 38.89 \mathrm{mmHg}, P=$ $0.016)$, a higher HR $(93.81 \pm 19.13 \mathrm{beats} / \mathrm{min}$ vs. $80.77 \pm 14.91$ beats $/ \mathrm{min}, P=0.014)$; additionally higher updated GRACE risk score $(6.81 \pm 12$ vs. $3.22 \pm 6.95, P=0.048$ ) compared to subgroup A2.
Subgroup A1 also showed significantly a higher number of in-hospital mortality (5/16 vs. $1 / 30, P=$ 0.015 ) than subgroup A2 (Tables 2 and 3).

Anterior location of f-QRS was present in 20 out of 46 patients (43.5\%) of the cases group. While inferior location of $f-Q R S$ was encountered in $76.1 \%$ of patients while the lateral location of $\mathrm{f}-\mathrm{QRS}$ was the least (21.7\%) in the patients studied (Fig. 3). The different fragmented QRS locations can have variable impacts on hemodynamics, the occurrence of cardiogenic shock and updated GRACE risk score, and in-hospital mortality. The Anterior f-QRS location showed significant statistical lower SBP, a higher HR, a higher incidence of cardiogenic shock (KILLIP class IV), a higher updated GRACE risk score $(P=0.033)$, and a higher incidence of in-hospital mortality $(P=0.004)$ compared to nonanterior fragmented-QRS location (Table 4).

\section{Discussion}

[8] acknowledged that despite numerous studies, the predictive value of $\mathrm{f}$-QRS in the 12-lead ECG in patients after acute coronary syndrome is controversial. Research carried out in large groups of patients provides conflicting results, therefore, there is a need to carry out a number of meta-analysis in order to draw the right conclusions. 
Table 1 General demographic characteristic, major risk factors, forms of ACS, (SBP and HR) on admission, positive cardiac biomarkers, location of STEMI, Killip class, risk stratifications

\begin{tabular}{|c|c|c|c|}
\hline & $\mathrm{f}-\mathrm{QRS}$ & Non f-QRS & $\boldsymbol{P}$ value \\
\hline Age, years & $52.52 \pm 10.04$ & $54.29 \pm 12.8$ & 0.480 \\
\hline Sex, $m / f$ & $40 / 6$ & $27 / 11$ & 0.071 \\
\hline Body weight, $\mathrm{kg}$ & $80.22 \pm 11.78$ & $79.42 \pm 8.94$ & 0.736 \\
\hline Smoking & $36 / 46$ & $24 / 38$ & 0.127 \\
\hline Dyslipidemia & $14 / 35$ & $16 / 33$ & 0481 \\
\hline HTN & $18 / 46$ & $16 / 38$ & 0.782 \\
\hline DM & $16 / 46$ & $11 / 38$ & 0.569 \\
\hline STEMI & $38 / 46$ & $27 / 38$ & 0.208 \\
\hline NSTEMI & $4 / 46$ & $7 / 38$ & 0.212 \\
\hline UA & $4 / 46$ & $4 / 38$ & 1.000 \\
\hline SBP, $\mathrm{mmHg}$ & $129.78 \pm 37.019$ & $129.46 \pm 34.717$ & 0.968 \\
\hline HR, bpm & $85.3 \pm 17.453$ & $78.18 \pm 19.154$ & 0.079 \\
\hline Abnormal cardiac biomarkers & $41 / 46$ & $32 / 38$ & 0.534 \\
\hline STEMI in AS zone & $18 / 38$ & $12 / 25$ & 0.961 \\
\hline STEMI in IL zone & $20 / 38$ & $13 / 25$ & 0.961 \\
\hline Killip I & $33 / 46$ & $21 / 38$ & 0.117 \\
\hline Killip II & $9 / 46$ & $13 / 38$ & 0.129 \\
\hline Killip III & $0 / 46$ & $1 / 38$ & 0.452 \\
\hline Killip IV & $4 / 46$ & $3 / 38$ & 1.000 \\
\hline Updated GRACE score & $4.42 \pm 8.97$ & $4.24 \pm 6.56$ & 0.8999 \\
\hline High risk GRACE & $13 / 45$ & $15 / 37$ & 0.268 \\
\hline Intermediate risk GRACE & $22 / 45$ & $12 / 37$ & 0.132 \\
\hline Low risk GRACE & $10 / 45$ & $10 / 37$ & 0.614 \\
\hline
\end{tabular}

AS antroseptal; IL infrolateral; DM diabetes mellitus; HR heart rate; HTN hypertension; IL inferolateral; NSTEMI non-ST elevation myocardial infarction; SBP systolic blood pressure; STEMI ST elevation myocardial infarction; UA unstable angina

In the present study, we meant to detect whether the $\mathrm{f}$-QRS presence has any role in the prediction of poor outcomes in patients with acute coronary syndrome. During the study, we have found that it is not the mere presence of $\mathrm{f}-\mathrm{QRS}$ that affect the outcomes, but its location and the number of fragmented leads that matter.

In our study, f-QRS presented in 46 out of 84 patients $(54.8 \%)$ with acute coronary syndrome. These 2 groups did not present any significant difference regarding general demographic characteristics and the most important risk factors of coronary heart disease. These results matched those in [3] by Bekler and associates. On examination of the patients enrolled in the study, measurement of SBP and HR as vital signs showed no significant difference between both groups.

[8] compared HR between patients with acute coronary syndrome according to the occurrence of $\mathrm{f}-\mathrm{QRS}$ using Holter, average of HR between both groups was not statistically significant ( $P$ value was 0.33 ).

There was no significant relation between both main groups regarding positive cardiac bio-markers $(P=$
$0.534)$, in the study conducted by [1], $P$ value of elevated $\mathrm{CPK}$ and troponin I between $\mathrm{f}-\mathrm{QRS}$ group and non $\mathrm{f}$ QRS group was 0.39 and 0.60 respectively.

We assessed the Killip class between both groups with more focus on Killip IV which represents cardiogenic shock. There were no significant differences between them, [10] defined heart failure as a Killip class > 1 , there was no significant difference between the three groups of the study (persistent $\mathrm{f}-\mathrm{QRS}$, transient $\mathrm{f}-\mathrm{QRS}$ and non $\mathrm{f}-\mathrm{QRS}$ ) as regards Killip class > 1 .

The updated GRACE risk score was higher in group (A) with no significant difference between both groups $(P=0.899)$. However, [4] succeeded to find a higher and significant GRACE score in group with $\mathrm{f}-\mathrm{QRS}$ than non $\mathrm{f}$-QRS group, this dissimilarity in both studies results is believed to be due to different patients populations as they excluded STEMI and UA from their study, our study included all variants of acute coronary syndrome.

In the term of in-hospital death, there was not any significant difference between the both groups $(P=>0.99)$. In NSTEMI, there was no significant difference between 


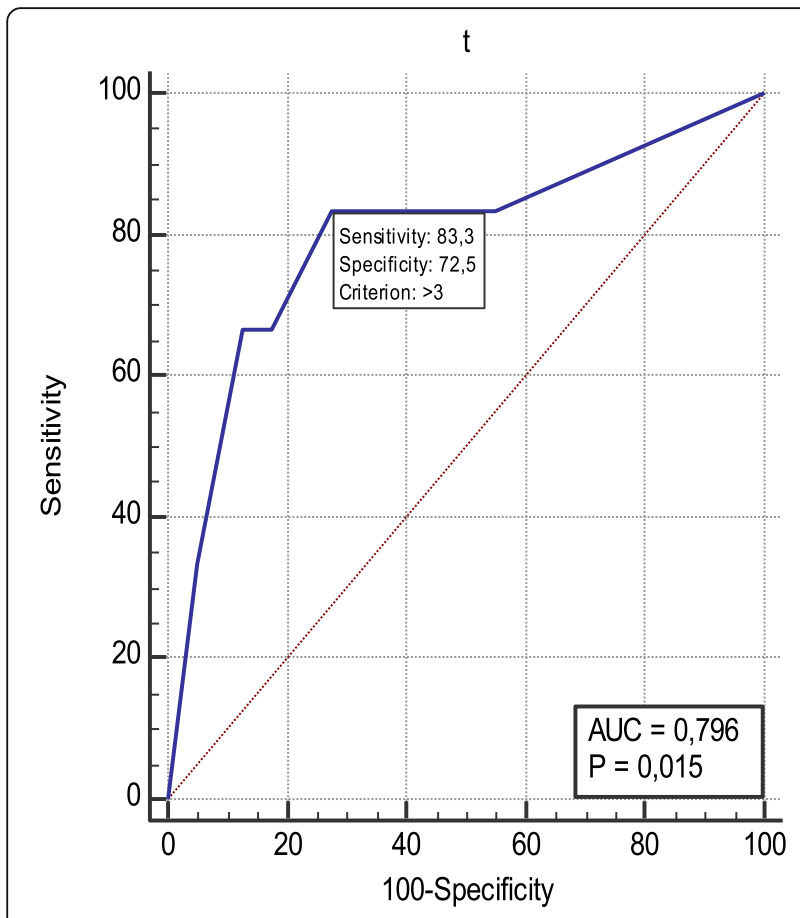

Fig. 2 Showing sensitivity and specificity of no. of leads with f-QRS to in-hospital death

f-QRS group and non f-QRS regarding mortality in the study conducted by [11]. From the above information, we can find that presence of f-QRS in ECG of patients with ACS does not add any significant prognostic value (Table 1), but the impact of number or location of fragmented leads has great value as seen next.

Receiver operator characteristic (ROC) analysis showed that greater than 3fragmented QRS was the optimum cutoff value for number of $\mathrm{f}-\mathrm{QRS}$ leads in predicting in-hospital mortality (Fig. 2), these findings are almost in agreement with the study conducted by [14] where it concluded that the presence of $\geq 3 \mathrm{f}-\mathrm{QRS}$ leads is independently connected with cardiac mortality or hospitalization for heart failure in 170 patients with past MI .Thereby, we divided the cases group into 2 subgroups according to the numbers of $f-Q R S$ leads. Subgroup (A1) included patients with more than $3 \mathrm{f}-\mathrm{QRS}$ leads and subgroup (A2) included patients with 3 or less $\mathrm{f}-\mathrm{QRS}$ leads. Moreover, the case group was also divided according to the location of $\mathrm{f}-\mathrm{QRS}$ into three groups (anterior, lateral, and inferior). Subgroup (A1) showed a significant difference in the term of SBP and HR readings on admission where it showed lower and higher values respectively than subgroup (A2) (Tables 2 and 3). Anterior f-QRS was also associated with significant higher HR and lower SBP than non-anterior $f-Q R S$ (Table 4). Number of $\mathrm{f}-\mathrm{QRS}$ was not significantly related to Killip IV and both subgroups did not show any significant difference $(P=0.114)$. Only anterior $\mathrm{f}-\mathrm{QRS}$
Table 2 Echocardiography data

\begin{tabular}{llll}
\hline & f-QRS & Non f-QRS & $\begin{array}{l}\boldsymbol{P} \\
\text { value }\end{array}$ \\
\hline LVEDD, mm & $52.98 \pm 7.097$ & $49.44 \pm 6.89$ & 0.033 \\
LVEF, (\%) & $53.78 \pm$ & $55.67 \pm$ & 0.493 \\
& 12.016 & 11.962 & \\
No systolic dysfunction & $28 / 41$ & $25 / 36$ & 0.913 \\
Mild systolic dysfunction & $9 / 41$ & $8 / 36$ & 0.977 \\
Moderate systolic & $2 / 41$ & $3 / 36$ & 0.660 \\
dysfunction & & & \\
Severe systolic dysfunction & $2 / 41$ & $0 / 36$ & 0.496 \\
No diastolic dysfunction & $0 / 39$ & $1 / 32$ & 0.451 \\
Diastolic dysfunction I & $28 / 39$ & $19 / 32$ & 0.271 \\
Diastolic dysfunction II & $9 / 39$ & $10 / 32$ & 0.439 \\
Diastolic dysfunction III & $2 / 39$ & $2 / 32$ & 1.000 \\
No MR & $22 / 41$ & $22 / 35$ & 0.418 \\
Mild MR & $14 / 41$ & $6 / 35$ & 0.093 \\
Moderate MR & $4 / 41$ & $7 / 35$ & 0.327 \\
Severe MR & $1 / 41$ & $0 / 35$ & 1.000 \\
In-hospital death & $6 / 46$ & $5 / 38$ & 1.000 \\
\hline
\end{tabular}

$\angle V E D D$ left ventricle end diastolic diameter; $M R$ mitral regurgitation; $P C I$ percutaneous coronary intervention; $R C A$ right coronary artery; SBP systolic blood pressure

when compared to non-anterior $\mathrm{f}-\mathrm{QRS}$ showed the significant difference $(P=0.030)$. Patients in the subgroup (A1) had a higher and significant updated GRACE risk score than subgroup (A2). Furthermore, anterior location of $\mathrm{f}-\mathrm{QRS}$ had statistically significant higher updated GRACE risk score $(P=0.033)$ than non-anterior $\mathrm{f}$-QRS.

Finally, in terms of in-hospital death, subgroup (A1) showed a significantly higher incidence of in-hospital death in relation to subgroup (A2) $(P=0.015)$ [12]., in their research on the value of the number of fragmented QRS leads in the prediction of in-hospital mortality in acute STEMI patients treated with primary PCI. They concluded that the number of $\mathrm{f}-\mathrm{QRS}$ leads was significantly higher among patients with in-hospital mortality.

Table 3 The important results of the 2 subgroups (A1) and (A2)

\begin{tabular}{|c|c|c|c|}
\hline & $\begin{array}{l}\text { Subgroup }(\mathrm{A} 1)> \\
\text { 3fQRS }\end{array}$ & $\begin{array}{l}\text { Subgroup (A2) } \leq \\
\text { 3f-QRS }\end{array}$ & $\begin{array}{l}P \\
\text { value }\end{array}$ \\
\hline SBP, $\mathrm{mmHg}$ & $111.33 \pm 25.03$ & $139 \pm 38.89$ & 0.016 \\
\hline Heart rate, bpm & $93.81 \pm 19.13$ & $80.77 \pm 14.91$ & 0.014 \\
\hline $\begin{array}{l}\text { Abnormal cardiac } \\
\text { biomarkers }\end{array}$ & $13 / 16$ & $28 / 30$ & 0.325 \\
\hline Killip (IV) & $3 / 16$ & $1 / 30$ & 0.114 \\
\hline In-hospital death & $5 / 16$ & $1 / 30$ & 0.015 \\
\hline Updated GRACE score & $6.81 \pm 12$ & $3.22 \pm 6.95$ & 0.048 \\
\hline LVEF (\%) & $48.08 \pm 13.07$ & $56.14 \pm 10.92$ & 0.049 \\
\hline
\end{tabular}

LVEF left ventricle ejection fraction; SBP systolic blood pressure 


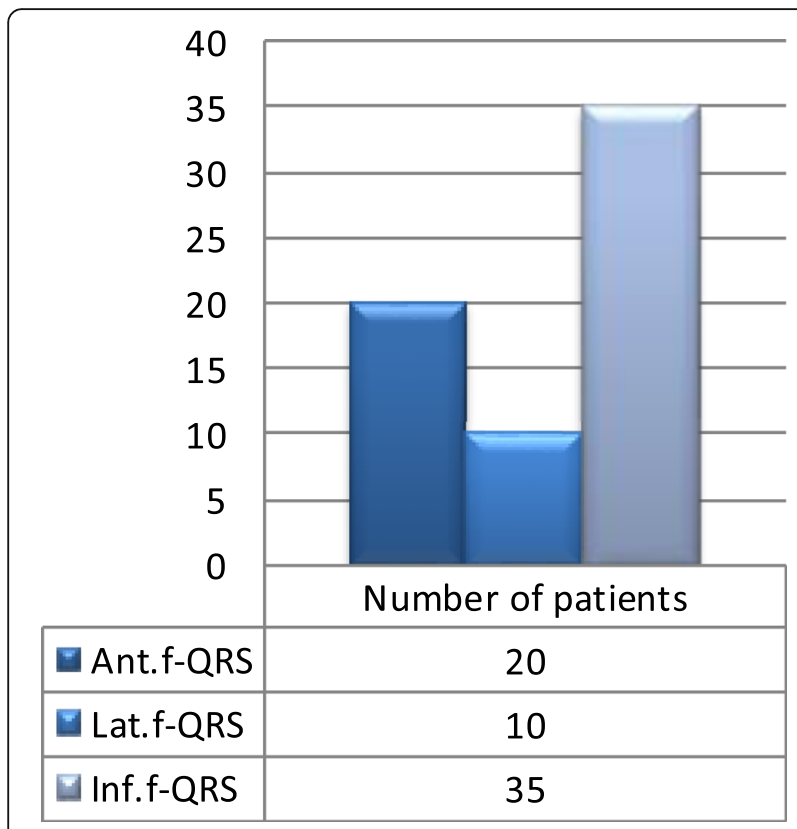

Fig. 3 Frequency of distribution of location of $\mathrm{f}-\mathrm{QRS}$ lead

Anterior f-QRS location was associated significantly with in-hospital death. Terho and colleagues concluded in [13], that f-QRS in lateral leads in patients with confirmed cardiac diseases was associated with higher risk of all-cause death, it is worth noting that they considered lateral leads territory on ECG was (I, aVL, V4 to V6) while in our study we considered lateral $\mathrm{f}$-QRS territory only in ( I, aVL, and V6) and anterior leads ( V1 to V5) as $[10,15]$ have done. Based on the above analysis, our explanation to the non-significant result between the two major groups is thought to be due to that $\mathrm{f}-\mathrm{QRS}$ in 2 and 3 leads presented in $39 \%$ and $26 \%$ of the fragmented group respectively.

Table 4 Relations between anterior f-QRS and some important medical results in the cases group

\begin{tabular}{llll}
\hline & $\begin{array}{l}\text { Anterior } \mathrm{f}- \\
\text { QRS }\end{array}$ & $\begin{array}{l}\text { Non-anterior } \mathrm{f}- \\
\text { QRS }\end{array}$ & $\begin{array}{l}\boldsymbol{P} \\
\text { value }\end{array}$ \\
\hline SBP, mmHg & $112.6 \pm 23.5$ & $142.31 \pm 40.33$ & 0.006 \\
HR, bpm & $91.3 \pm 18.62$ & $80.7 \pm 15.3$ & 0.040 \\
$\begin{array}{l}\text { Abnormal cardiac } \\
\text { biomarkers }\end{array}$ & $17 / 20$ & $24 / 26$ & 0.64 \\
Killip (IV) & & & \\
$\begin{array}{l}\text { Updated GRACE score } \\
\text { LVEF (\%) }\end{array}$ & $7 / 20$ & $0 / 26$ & 0.030 \\
In-hospital death & $48.7 \pm 12.17$ & $2.03 \pm 1.72$ & 0.033 \\
\hline
\end{tabular}

HR heart rate; LVEF left ventricle ejection fraction; SBP systolic blood pressure

\section{Study limitations}

Study limitations include the relatively small sample, retrospective with less precisive and available data, no inclusion of $\mathrm{f}-\mathrm{QRS}$ in aVR, V3r, and V4r leads, no study of arrhythmia, re-infarction or long term mortality, and finally, the low pass filter that is optimally used in order to detect $\mathrm{f}-\mathrm{QRS}$ is $100-150 \mathrm{~Hz}$, it may be masked when using filter with a lower setting.

\section{Conclusion}

F-QRS in > 3 leads and anterior $\mathrm{f}-\mathrm{QRS}$ have significant lower systolic blood pressure and heart rate and significant higher heart rate, updated GRACE risk score and incidence of in-hospital mortality. Moreover, anterior fQRS is associated with higher incidence of Killip IV (cardiogenic shock).

\section{Recommendation}

The mere presence of $\mathrm{f}-\mathrm{QRS}$ on 12 leads surface ECG in patients with ACS is not enough to predict the prognosis; however, using the number if greater than 3f-QRS leads and the anterior location of $\mathrm{f}-\mathrm{QRS}$ leads is of a great value to predict the prognosis, the occurrence of cardiogenic shock and in-hospital mortality (Fig. 3).

\section{Abbreviations}

ACS: Acute coronary syndrome; AF: Atrial fibrillation; BBB: Bundle branch block; CABG: Coronary artery bypass graft; CAD: Coronary artery diseases;

CHD: Coronary heart disease; DM: Diabetes mellitus; ECG: Electrocardiogram; EF: Ejection fraction; f-QR: Fragmented QRS; GRACE: Global Registry of Acute Coronary Events; HR: Heart rate; HTN: Hypertension; Hz: Hertz; MACE: Major advanced cardiac events; MI: Myocardial infarction; NSTEMI: Non-ST elevation myocardial infarction; PCl: Percutaneous coronary intervention; ROC: Receiver operator characteristic; SBP: Systolic blood pressure; SD: Standard deviation;

STEMI: ST elevation myocardial infarction; UA: Unstable angina

\section{Acknowledgements}

N/A

\section{Authors' contributions}

ASY collected the data and performed the statistical analysis. NIA, MIE, and MAE participated in the study design, reviewed statistical results, and coordinated and helped to draft the manuscript. All authors have read and approved the manuscript.

Funding

Self-funded

Availability of data and materials

Data and material are available upon request.

Ethics approval and consent to participate

Our retrospective non-interventional non-invasive study was done after approval and informed oral consent of all patients or their relatives and all personal patients' data are hidden carefully.

The consent was oral because the study was retrospective noninterventional, we just looked into the papers. Bringing the patients or their relatives while most of them are living in faraway provinces for a written consent would be really difficult.

The study protocol was approved by the Critical Care Department; Faculty of Medicine Cairo University Ethical Committee followed by the approval of the Faculty of Medicine Kasr Al-Ainy College Council; Cairo University, Egypt. 


\section{Consent for publication}

Not applicable

\section{Competing interests}

The authors disclose there is no conflict of interests.

Received: 20 May 2019 Accepted: 9 July 2020

Published online: 23 July 2020

\section{References}

1. Akbarzadeh F, Pourafkari L, Ghaffari S, Hashemi M, Sadeghi-Bazargani H (2013) Predictive value of the fragmented QRS complex in 6-month mortality and morbidity following acute coronary syndrome. Int J Gen Med 6:399-404

2. Ari H, Cetinkaya S, Ari S, Koca V, Bozat T (2012) The prognostic significance of a fragmented QRS complex after primary percutaneous coronary intervention. Heart Vessels (Abstract) 27(1):20-28

3. Bekler A, Barutçu A, Tenekecioglu E et al (2015) The relationship between fragmented QRS complexes and SYNTAX and Gensini scores in patients with acute coronary syndrome. Kardiol Pol 73(4):246-254

4. Bozbeyoğlu E, Yıldırımtürk Ö, Yazıcı S et al (2015) Fragmented QRS on admission electrocardiography predicts long-term mortality in patients with non-ST segment elevation myocardial infarction. Ann Noninvasive Electrocardiol 00(0):1-6

5. Das MK, Khan B, Jacob S, Kumar A, Mahenthiran J (2006) Significance of a fragmented QRS complex vs. a $\mathrm{Q}$ wave in patients with coronary artery disease. Circulation 113:2495-2501

6. Das MK, Suradi H, Maskoun W et al (2008) Fragmented wide QRS on a 12lead ECG: a sign of myocardial scar and poor prognosis. Circ Arrhythm Electrophysiol 1:258-268

7. Das MK, Michael MA, Suradi $\mathrm{H}$ et al (2009 Dec 15) Usefulness of fragmented QRS on a 12-lead electrocardiogram in acute coronary syndrome for predicting mortality. Am J Cardiol (Abstract) 104(12):1631-1637

8. Daszyk AM, Zygmund K, Mitręga KA, Cebula S, Kalarus Z, Średniawa B. Fragmentation of the QRS complex in patients with acute coronary syndrome treated invasively. Kardiol Pol. 2016.

9. Flowers NC, Horan LG, Thomas JR, Tolleson WJ (2012) The anatomic basis for high-frequency components in the electrocardiogram. Circulation, 1969; 39: 531-539. Cited in Pietrasik G, Zaręba W. QRS fragmentation: diagnostic and prognostic significance. Cardiol J 19(2):114-121

10. Lorgis L, Jourda F, Hachet O, Zeller M et al (2013) Prognostic value of fragmented QRS on a 12-lead ECG in patients with acute myocardial infarction. Heart Lung 42(5):326-331

11. Sheng QH, Hsu CC, Li JP, Hong T, Huo Y (2014 Jan) Correlation between fragmented QRS and the short-term prognosis of patients with acute myocardial infarction. J Zhejiang Univ Sci B 15(1):67-74

12. Tanriverdi Z, Dursun H, Kaya D (2016) The importance of the number of leads with f-QRS for predicting in-hospital mortality in acute STEMI patients treated with primary PCI. Ann Noninvasive Electrocardiol 21(4):413-419

13. Terho HK, Tikkanen JT, Junttila JM et al (2014 Jul 1) Prevalence and prognostic significance of fragmented QRS complex in middle-aged subjects with and without clinical or electrocardiographic evidence of cardiac disease. Am J Cardiol(Abstract) 114(1):141-147

14. Torigoe K, Tamura A, Kawano Y, Shinozaki K, Kotoku M, Kadota J (2012) The number of leads with fragmented QRS is independently associated with cardiac death or hospitalization for heart failure in patients with prior myocardial infarction. J Cardiol 59(1):36-41

15. Wang DD, Tibrewala A, Nguygen $P$; et al. Fragmented QRS on surface electrocardiogram is not a reliable predictor of myocardial scar, angiographic coronary disease or long term adverse outcomes. Cardiovasc Diagn Ther. 2014 Aug;4(4):279-86.Erratum in Cardiovasc Diagn Ther. 2014 Oct:4(5):411

16. Wilson PWF and Douglas PS. Epidemiology of coronary heart disease. In: uptodate, Post TW (Ed), uptodate, Waltham,MA, 2014

\section{Publisher's Note}

Springer Nature remains neutral with regard to jurisdictional claims in published maps and institutional affiliations.

\section{Submit your manuscript to a SpringerOpen ${ }^{\circ}$ journal and benefit from:}

- Convenient online submission

- Rigorous peer review

- Open access: articles freely available online

High visibility within the field

- Retaining the copyright to your article

Submit your next manuscript at $\boldsymbol{\nabla}$ springeropen.com 